\title{
ON MAPS FOR DISCOVERY: DID THE PERIODIC TABLE GUIDE ELEMENTAL DISCOVERY?
}

\author{
M. KOCHEN, J. LANSING \\ Mental Health Research Institute The University of Michigan, \\ Ann Arbor, MI 48109 (USA)
}

(Received June 1, 1984)

\begin{abstract}
The metaphor of "maps" as cognitive tools aiding scientific discovery may be particularly appropriate for discussing the role of the periodic table of the elements in the progress of chemistry. In a tribute to the contributions of Derek Price, the use of maps, their advantages and disadvantages, and changes in the table are explored. The authors conclude that the table did serve as a general guide to discovery but that more insightful models of a different sort also played an important role.
\end{abstract}

\section{Introduction}

Derek Price expressed his sense of wonder about the possibility of representing knowledge as a map. It consisted of subjects such as "plate tectonics" or "insulin chemistry" that were analogous to molecular activities. He envisaged something like an "operations room map" of the entire field of scientific and technical knowledge, with lights flashing at some site to indicate a likely break in molecular biology in China. ${ }^{1}$

Perhaps "tomogram" would be a more accurate name than "map" for what he had in mind. But "map" is more appropriate as a metaphor. Price's most fruitful scientific thought took place at the level of metaphor. In this case he imagined one of several constantly changing maps of the state of knowledge, as a guide for scientists, science policy-makers and science-watchers. We, his intellectual heirs, and having for a long time used the map-metaphor, will follow his terminology.

If subjects or topics are analogous to molecules, then sciertific "concepts" are analogous to the atoms, as the nodes in a "semantic net". ${ }^{2}$ In our 1962 construction of a concept-map, stimulated by a paper of Stevens ${ }^{3}$, a person's knowledge about a concept such as "Hydrogen" (or R in general) was represented at any time by a set of simple sentences including the term denoting the concept. The sentences were of the form RLS, where $L$ denotes a predicate and $S$ could be an expression that might be another sentence or a term denoting another concept. Much of what is now represented by relations (in a relational database), by frames or by production rules could be 


\section{KOCHEN, J. LANSING: MAPS FOR DISCOVERY}

captured in the full version of this system, which was also embedded in an applied predicate calculus.

Price also had a predilection for self-referential phrases, such as the "science of science". It is thus wholly his style to apply his notion of a map in which scientific concepts are analogous to atoms to atoms literally. Indeed, he was one of the first to plot the number of chemical elements known as a function of time. ${ }^{4} \mathrm{He}$ must surely have asked himself the questions, whether the discovery of the elements was guided by the periodic table in much the way certain explorers are guided by a topographic map, and whether new evidence led to changes in the map.

We were led to use the periodic table as a map in the search for some representation of knowledge space with some metric properties in which we could study diffusion of knowledge somewhat analogously to physical diffusion. We wanted to extend a model for the growth of two interacting specialties, such as "low-dimensional topology" and "differential geometry" to take into account the "distance" between these specialties. Thus, we thought that discoveries about $\mathrm{Cl}$ might use and be stimulated by prior discoveries about $\mathrm{F}, \mathrm{Br}, \mathrm{S}$ or $\mathrm{K}$ (its neighbors in Mendeleev's table) more recently than by discoveries about elements in the table that are further from $\mathrm{Cl}$. Historical data, such as might today be obtained by citation analysis, are not available at this level of detail.

We therefore asked the more general question: Did the periodic table guide discovery of later elements? If so, how does the process of discovery relate to following a map, and how is evidence used to modify a map? In what follows, we discuss the use of maps in discovery, stages and factors in the history of elemental discovery with emphasis on the periodic table as a software or conceptual tool, the role of technology (hardware) in elemental discovery, how the table was changed and how it misguided discovery before it was changed again.

\section{Maps in the discovery process}

Among the diverse stereotypes of discoverers, there are two that are useful for scientific investigation into discovery processes. The first is the systematic researcher. He has a repertoire of methods and professional skill in applying them. He comes prepared with a mental or physical map, clear objectives and hypotheses. He works within an established paradigm and poses questions concensually regarded as important. He writes the kinds of research proposals that easily get funded and manages his research team very effectively. His results fit into well-defined niches, and his publications get accepted in mainstream journals. His experiments are generally confirmatory. 
The second type of discoverer is a less systematic explorer. He invents or procures methods and tools as he needs them. He gambles on stumbling upon the unexpected. He tends to be unconventional and opportunistic. When he does succeed, he often blazes a new trail rather than widening or paving an existing one. He discovers new niches that his results are the first to populate. His experiments tend to be exploratory. External maps are often not available.

Both kinds of discoverers use internal maps to organize and guide their creative thinking and their research. These maps are organized knowledge structures, built up with concepts and ideas. Both make their discoveries by actions rather than by passively waiting for ideas or observations to come to them. Both have what Pasteur called "prepared minds" that enable them to recognize chance observation as important and to act on them. It is these actions, amplified by scientific technology, that are guided by maps. Or perhaps they are misguided.

In this paper, we use the periodic table of the chemical elements, as it evolved throughout its history, as an example of a map or representation of knowledge space. We ask if the productivity of a discoverer's mind and the diffusion of knowledge can be explained as motion in this knowledge space. We ask about the role the periodic table has actually played in the history of elemental discoveries in chemistry.

\section{Stages in the history of elemental discovery}

If the number of chemical elements known is plotted as a function of time since the year $1730^{1}$, a logistic growth curve results (Fig. 1). This is not surprising, since most growth laws have this form ${ }^{6}$ starting with an exponential rise and followed by a leveling off to an asymptote. If $\mathrm{k}(\mathrm{t})$ is the number of elements, or items of information aoout elements known by time $t$, and the rate of change, $\mathrm{dk} / \mathrm{dt}$, is proportional to both $\mathrm{k}$ and to $\mathrm{n}-\mathrm{k}$, the number yet to be discovered, then the solution to this differential equation is the logistic growth law. Price postulated three major periods of elemental discovery. First are the years surrounding 1807 and Humphrey Davy's heyday at the Royal Academy. The second is the turn of the nineteenth century. The third is the period in the late 1930's to early 1940's with the discovery of transuranium elements.

The logistic growth law was derived from first principles in the context of a new conceptualization of scientific specialties. In applying these ideas to the growth law of elemental discovery we must ask ourselves a number of questions: In what sense does the discovery of new elements represent growth in science? What factors contribute to periods with large numbers of discoveries and what factors contribute to periods with small numbers of discoveries? Does the history of elemental 


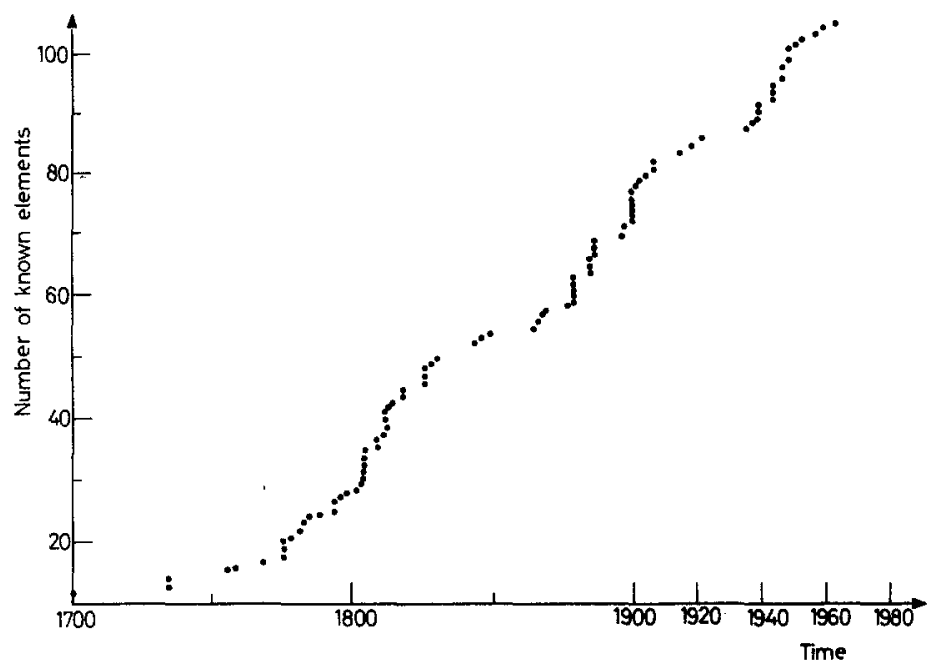

Fig. 1. The number of known chemical elements as a function of time

discovery truly follow a logistic curve and if so how may we compare the productivity of these phases?

If one examines carefully the curve of the path of elemental discovery in conjunction with the history that it represent there are twelve rather than three distinguishable phases. (Table I) Like Price, we start our discussion with those discovered after 1700 . This is not to say that the first two periods of elemental discovery, the ancient and alchemical phases, are not fascinating stories in themselves. ${ }^{7}$ We start with the third period of chemistry extending from 1700-1766, the Phlogiston Phase.

Table 1

The different phases and productivity rates

\begin{tabular}{lcc}
\multicolumn{1}{c}{ Interval } & Years & Productivity rate \\
\hline Phlogiston phase & $1700-1766$ & 0.06 \\
Gas phase & $1766-1780$ & 0.36 \\
Post-revolutionary phase & $1780-1800$ & 0.40 \\
Alkali phase & $1800-1815$ & 1.07 \\
Dormant phase & $1815-1855$ & 0.25 \\
Spectroscopic phase & $1855-1865$ & 0.40 \\
Rare Earth phase & $1865-1890$ & 0.34 \\
Noble-Radioactive phase & $1890-1910$ & 0.65 \\
Quantum phase & $1910-1935$ & 0.12 \\
Nuclear phase & 1935 -present & 0.25 \\
\hline
\end{tabular}


In the year 1700 there were thirteen known chemical elements, such as oxygen and mercury, that were known to the Ancients. A simple way of comparing the productivity rate of each phase is to compare the ratio of discoveries to time passage (see Table 1). By examining the curve of Figure 1 and using these figures we can easily quantify the more and less productive phases. By delineating ten rather than three phases of discovery we can examine the growth curve more carefully and provide more explanations for surges and gaps.

\section{Factors in elemental discovery and the Periodic Table}

It will be shown that a relation exists between developments in chemistry and the discovery of elements. Two major factors in elemental discovery are breakthroughs in chemical and physical theories and breakthroughs in technology. After the year 1885 one of the most important factors in elemental discovery was the way in which scientists organize what is known and extend this knowledge. The concept of a knowledge space has been put forth by many authors. The periodic table of elements has provided chemists and physicists with a knowledge space since its development in the early 1870's. To understand the growth of elemental discovery one must follow carefully the heuristic development of the periodic table. While it is capable of making predictions and opening doors to discovery, it has also been known to provide a red herring and it has led scientists astray. To understand what factors contribute to these periods of discovery it is best to begin with the discovery of the table itself.

During the late eighteenth and early nineteenth centuries a number of scientists began composing lists of the known elements- Morveau, Dalton, Thomson, Wollaston, Berzelius, Dumas. The first true attempt at a periodic listing of the elements occured in 1829 with Johann Wolfgang Dobereiner and the Law of Triads. This law stated that it was possible to arrange elements into groups of three or "triads" such that the atomic weight of one is approximately equal to the average of the atomic weights of the other two. ${ }^{8}$ An example of such a triad is $\mathrm{Cl}_{\mathrm{Br}} \mathrm{I}$. This occurred during the 7 th stage, the "dormant" phase, 1815-1855.

In 1862, during the "spectroscopic" phase (1855-1865), Alexandre-Emile Beguyer de Chancourtois devised a table drawing upon the work of Dumas and Cannizaro. ${ }^{9}$ His "telluric screw"10 was similar to, though not as complete as the Law of Octaves. This law was presented in a table by John Alexander Newlands. ${ }^{11}$ His table divided 62 elements into eight vertical and seven horizontal families. The recurring elements were separated by eight elements like musical octaves. Both Newlands and Chancourtois 


\section{KOCHEN, J. LANSING: MAPS FOR DISCOVERY}

Table 2

Comparison of predicted and actual properties of germanium

Properties of eka-silicon as predicted by Mendeleyev in 1871 and of germanium discovered by Winkler in 1886 (values revised later are shown in brackets)

\begin{tabular}{|c|c|c|}
\hline Property & Predicted for eka-silicon (Es) & Found for germanium (Ge) \\
\hline \multicolumn{3}{|l|}{ Element } \\
\hline Atomic weight & 72 & 72.60 \\
\hline Valency & $\begin{array}{l}\text { Tetravalent, but can exhibit } \\
\text { lower valency states }\end{array}$ & 4 and 2 \\
\hline Specific heat & 0.073 & 0.076 \\
\hline Atomic volume & 13 & 13.4 \\
\hline Specific weight & 5.5 & density $5.35(5.47)$ \\
\hline Fusibility and volatility & $\begin{array}{l}\text { Meltable metal that can become } \\
\text { volatile at high temperature }\end{array}$ & $\begin{array}{l}\left.\text { (m.p. } 958.5^{\circ} \mathrm{C}\right) \\
\left.\text { (b.p. } 2700^{\circ} \mathrm{C}\right)\end{array}$ \\
\hline \multicolumn{3}{|l|}{ Oxide } \\
\hline Highest oxide & $\mathrm{EsO}_{2}$ & $\mathrm{GeO}_{2}$ \\
\hline Molecular volume & 22 & 22.2 \\
\hline Specific weight & 4.7 & $(4.703)$ \\
\hline Chemical properties & $\begin{array}{l}\text { Acidic, but can show some basic } \\
\text { properties }\end{array}$ & $\begin{array}{l}\text { Amphoteric, with predominance } \\
\text { of acidic properties }\end{array}$ \\
\hline \multicolumn{3}{|c|}{ P- } \\
\hline Fluoride & $\mathrm{EsF}_{4}$, not a gas & $\mathrm{GeF}_{4}, 3 \mathrm{H}_{2} \mathrm{O}$, solid \\
\hline Highest chloride & $\mathrm{EsCl}_{4}$, liquid & $\mathrm{GeCl}_{4}$, liquid \\
\hline m.p. & $90^{\circ} \mathrm{C}$ & $85^{\circ} \mathrm{C}\left(86.5^{\circ} \mathrm{C}\right)$ \\
\hline Specific weight & 1.9 & density 1.879 \\
\hline Chemical properties & Decomposed by water & Readily hydrolysed by water \\
\hline \multirow[t]{2}{*}{ Hydrogen compounds } & $\begin{array}{l}\text { Hydrogeneous compounds } \\
\text { might be also expected, } \\
\text { especially } \mathrm{EsH}_{4}\end{array}$ & $\begin{array}{l}\mathrm{GeH}_{4} \text { and other germanium } \\
\text { hydrides have been prepared }\end{array}$ \\
\hline & $\begin{array}{l}\mathrm{EsH}_{4} \text { should be readily } \\
\text { decomposed to hydrogen and } \\
\text { metal }\end{array}$ & $\begin{array}{l}\mathrm{GeH}_{4} \text { decomposes at } \\
350{ }^{\circ} \mathrm{C}\end{array}$ \\
\hline Organometallic compound & $\begin{array}{l}\text { Will, of course, form organo- } \\
\text { metallic compounds }\end{array}$ & $\begin{array}{l}\text { Numerous germanium organic } \\
\text { compounds have been obtained }\end{array}$ \\
\hline Typical compund & $\mathrm{Es}\left(\mathrm{C}_{2} \mathrm{H}_{5}\right)_{4}$ & $\mathrm{Ge}\left(\mathrm{C}_{2} \mathrm{H}_{5}\right)_{4}$ \\
\hline b.p. & $160^{\circ} \mathrm{C}$ & $163.5^{\circ} \mathrm{C}$ \\
\hline Specific weight & 0.96 & 0.991 \\
\hline
\end{tabular}

place an almost mystical emphasis upon numbers. This mysticism caused them to suffer a lack of credibility among their colleagues.

Almost simultaneously with Newlands, Lothar Meyer and William Odling developed tables in the mid-1860's. ${ }^{12}$ Though Meyer's table was not actually published until 
after his death, both of these tables were of medium length and arranged the elements in order of increasing atomic weights.

In 1869 the Periodic Law was discovered by Dimitri Ivanovich Mendeleev. Though it was evident that there were precursors, and he was not the first to use the concept of periodicity, ${ }^{13}$ he is generally accredited with its discovery. This occurred during the "Rare Earth" phase, 1865-1890.

Mendeleev was still recovering from a fever on March 6, 1869. On that day the announcement of his periodic table was made to the Russian Chemical Society by his colleague, N.A. Menshutkin. The table was well-received despite a puzzling feature: it contained blank spaces. It is said that as the chemists filed out of the meeting they were concerned about these gaps-how could there be such blank spaces in nature? In a later paper Mendeleev would explain their meaning.

Mendeleev was so convinced by his table that he reversed the positions of elements- $\mathrm{Co}$ and $\mathrm{Ni}, \mathrm{Te}$ and $\mathrm{I}-$ corrected valencies and atomic weights- $\mathrm{In}, \mathrm{Cd}$, and $\mathrm{Ce}-$ and left vacant positions for atomic weights 44,68 , and 72 . He predicted the existence of each of these elements as well as their properties from the fact that they were analogous to boron, aluminum, and gallium. Here we see an important example of the use of the periodic table as a map to predict. The predictions clearly show how Mendeleev used the map by analogical reasoning. Boisbaudran discovered eka-aluminium in 1874 and named it gallium after his home country. ${ }^{14}$ Scandium (eka-boron) was discovered by the Scandinavian Lars Nilson in 1879 and the German Winkler discovered germanium (eka-silicon) in 1885 . Table $\$ 2$ provides a comparison between the predicted and actual properties of the new element.

The predictive capabilities of the periodic table thus provided a new analytical tool for the discovery of elements. Obviously the original table (see Fig. 2) proposed by Mendeleev differs greatly from the periodic table of today. Though the modern table is not complete, as there are many possibilities for transuranium elements, we are fairly sure that the holes which we leave to fill are in the right places. The modern table was not developed until after the second world war.

\section{Effect of technology on discovery}

Within the same decade as the proposal of the periodic table another tool was being developed which played a major role in elemental discovery-spectroscopy. In 1822 Sir J.F.W. Herschel showed that passing the light of the characteristic flames of salts through a prism produces a spectrum of bright lines separated by dark spaces. In 1859 the color and position of bright spectral lines were investigated by Robert Wilhelm Bunsen and Gustav Robert Kirchhoff. They described the construction of a 


\section{ОПЫТЪ СИСТЕМЫ ЭЛЕМЕНТОВЪ.}

ОСНОВАННОИ НА НХ А АТОМНОМЪ ВТСЬ И ХИМНЧЕСКОНВ СХОДСТВВ.

$$
\begin{aligned}
& T_{1}=50 \quad Z r=90 \quad ?=180 . \\
& V=51 \quad \mathrm{Nb}=94 \quad \mathrm{Ta}=182 . \\
& C r=52 \quad M_{0}=96 \quad W=186 \text {. } \\
& M n=55 \quad R h=104,4 \quad P l=197,4 \text {. } \\
& F_{e}=56 \quad R_{u}=104.4 \quad I r=188 \\
& \mathrm{Ni}=\mathrm{C}_{0}=39 \quad \mathrm{PI}=106.0 \mathrm{OS}=199 \text {. } \\
& \mathrm{H}=1 \quad \mathrm{Cu}=6.3 .4 \mathrm{Ag}=108 \quad \mathrm{Hg}=200 \\
& \mathrm{Be}=9.4 \mathrm{Mg}=24 \quad \mathrm{Zn}=6.5 .2 \quad \mathrm{Cd}=112 \\
& B=11 \quad A l=27,4 \quad ?=68 \quad U r=116 \quad A u=197 ? \\
& C=12 \quad S_{1}=28 \quad ?=70 \quad S n=118 \\
& N=14 \quad P=31 \quad A S=75 \quad S b=122 \quad B 1=210 ? \\
& 0=16 \quad S=32 \quad \mathrm{Se}=79.4 \mathrm{Te}=128 \text { ? } \\
& \mathrm{F}=19 \quad \mathrm{Cl}=35.5 \mathrm{Br}=80 \quad \mathrm{l}=12,7 \\
& L_{L}=7 \quad \mathrm{Na}=23 \quad \mathrm{~K}=39 \quad \mathrm{Rb}=85.4 \quad \mathrm{C}_{5}=! 33 \quad \mathrm{Tl}=204 \\
& \mathrm{Ca}=40 \quad \mathrm{Sr}=87.0 \quad \mathrm{Ba}=137 \quad \mathrm{~Pb}=207 \\
& 7=4 j \quad C e=92 \\
& ? E_{r}=56 \quad \mathrm{~L} 3=94 \\
& 7 Y_{1}=60 \quad D_{1}=95 \\
& 2 \ln =75,6 \mathrm{Th}=118 \text { ? }
\end{aligned}
$$

\section{A Mangen beos}

Fig. 2. "An outline of the system of elements". A sheet circulated by Mendeleyev to Russian physicists and chemists 
spectroscope and opened new doors for chemical analysis, especially for aiding in the discovery of new elements. If the periodic table is analogous to a conceptual or software tool, these tools are analogous to hardware. Price has always stressed the importance of hardware and scientific instruments in the growth of science.

The work of Bunsen and Kirchhoff resulted in the spectroscopic phase of elemental discovery beginning with the 1860 discovery of caesium (named for a billiant blue line in its spectrum). During the next four years three new elements were discovered with the aid of this new tool, rubidium-named for its dark red spectrum, indium-named for its brilliant indigo line and thallium- named from the greek for a green twig. Along with terrestrial elements, spectroscopy was also used to analyze the spectrum of the sun. Fraunhofer lines were examined and it was shown in 1860 that sodium is present in the atmosphere. In 1868 Pierre Janssen and Sir Norman Lockeyer examined the sun's photosphere during an eclipse and found a yellow line in its spectrum which had not been in the spectrum of any element on earth. Lockeyer concluded that this indicated the existence of an extra-terrestrial substance which he named helium after the greek helios, the sun.

After the close of the spectroscopic phase and the subsequent Rare Earth phase, another important development occured in chemical analysis. The original work in liquifying gases began in 1799 with the French chemists Fourcroy and Guyton de Morveau. A major step was the discovery of the so-called critical temperature by Thomas Andreus in 1869. He showed that for each gas there exists a temperature such that no matter how much pressure is exerted, a gas cannot liquefy unless it is equal to or less than that temperature. This allowed chemists to transcend the threshold of what were thought to be permanent gases-previously uncondensable. In 1883 Karl Olszevski developed a method for the fractional distillation of liquid air. This technique, combined with perfected spectroscopic methods and the periodic table introduced one of the most exciting phases of elemental discovery- the noble-radioactive phase, 1890-1910.

In the year 1875 Henry Cavendish investigated the properties of what was then known as phlogisticated air (nitrogen). Following Priestley's experiments, he found that by discharging electric sparks combinations of oxygen and nitrogen took place. These oxides were removed by a solution of caustic potash. He continued to add more oxygen and remove nitrogen entirely. The oxygen was then absorbed by liver of sulphate (potassium sulphide). No matter how long he passed the sparks there always remained a small bubble of gas. This fact was subsequently ignored for a hundred years. 


\section{Changing the map}

In 1892 Baron Rayleigh found that the density of atmospheric nitrogen-the gas left after the removal of $\mathrm{O}_{2}$ from purified air-is greater than the density of nitrogen obtained from its compounds by $1 / 230$. Various conjectures were put forth by Rayleigh to axplain the difference but none were verified by experiment. William Ramsay and Rayleigh each succeeded in isolating a sample of this gas which would not combine with oxygen. Its density was found to be about 20 , compared with 14 for nitrogen. Crookes showed that its spectrum was unique. Ramsay tried repeatedly to bring the gas into combination with other elements with no result.

Ramsay and Raileigh shocked the British Association in June of 1894 with the e announcement of the discovery of the new element argon (named from the greek for the lazy one). With its discovery came the difficulty of locating its proper positioning in the periodic table. If one assumed the atomic weight of 40 , the logical spot was to insert it between potassium and calcium, but this disrupted the periodicity completely. Since the element was inert, normal chemical means were ineffective for determining its weight. Values of $7.8,20$, and 40 were considered along with speculation as to whether is was mono-, di-, or tri-atomic. There was much discussion of the existence of a whole period of elements between hydrogen and lithium. Earlier conjectures about the existence of an element known as infracarbon which was thought to have an atomic weight of 2.5 to 3 led to placing argon in this period and a search for other elements. People such as G.J. Stoney predicted six new elements, infraberyllium through infrafluorine to preserve the structure of the table. ${ }^{15}$

There were other scientists who speculated that the new "element" argon was not really an element at all but an allotrope of nitrogen (similar to ozone being an allotrope of oxygen). Some considered it to be transition element between chlorine and potassium. Still others, such as Gregori Wyrouboff and Nassini, went so far as to reject the table completely. If the map is no longer useful, throw it away.

Ramsay, who believed argon to be a transition element, continued working to see if it would form some compounds. He learned that a gas thought to be nitrogen was obtainable from certain minerals in Norway containing uranium (discovered in 1789 by Klaproth and named after the planet). The gas evolved had been examined by W.F. Hildebrand of the United States and declared to be nitrogen. Ramsay performed his own research and obtained after purification a small quantity of gas which was neither argon nor nitrogen. He provisionally named it krypton (for hidden) and sent a sample to Crookes for spectroscopic examination. On March 23, 1895 Ramsay received a telegram announcing "krypton is helium" and another inert gas was discovered. Helium lost the status of being an extra-terrestrial. 


\section{Maps can misguide}

The periodic table was revised by the evidence of the new family of inert gases. The change followed a classical path of deductive and inductive reasoning which led to a more complete and more accurate model of atomic structure.

At the close of the noble-radioactive phase (in the year 1910) a total of 85 elements were known. At this point the concept of atomic number became the fundamental basis for ordering elements. During the next phase of discovery, the quantum phase (1910-1935), only three elements were discovered. This left three gaps in the table for elements preceding uranium. As noted by Seaborg in his Priestley Medal Address of 1979:

The state of understanding of the atomic nucleus was such in the 1930's that it could be shown that the missing elements were all radioactive with such short half-lives that their existence in appreciable concentration on earth was not possible. ${ }^{16}$

During the mid-thirties, Enrico Fermi and others, guided by the periodic table, developed a number of radioactive products by bombarding uranium with neutrons. It was believed that these products were exhibiting properties of "transuranium elements" similar to osmium and platinum which were listed directly above them. In 1938, the discovery of fission by Hahn and Strassman helped to show that this interpretation was incorrect. They were producing radioactive isotopes of elements such as barium and lanthanum, rather than new elements.

During 1940 two new elements were synthesized, neptunium and plutonium. Chemical analysis showed that their properties were similar to uranium and not at all like rhenium and osmium. The periodic table had misled the research of the late 1930 's by causing scientists to identify the wrong properties when synthesizing new elements. The problem now was where to insert these elements in the table. The conjecture was made that since uranium, neptunium and plutonium exhibited similarities, perhaps they formed a uranide group.

Experiments to synthesize elements 95 and 96 were based on this hypothesis. It was believed that these undiscovered elements should fit the pattern and exhibit chemical similarity to neptumium and plutonium. Once again the periodic table served to misguide scientific research. The anticipated properties simply were not found.

A breakthrough finally occured with the work of Glenn Seaborg.

... in 1944 I conceived the idea that perhaps all the known elements heavier than actinium were misplaced on the periodic table. The theory advanced was that these elements heavier than actinium might constitute a second series similar to the series of "rare-earth" or "lanthanide" elements. .. This would mean that all these heavier elements really belong with actinium-directly after radium in the periodic table-just as the known lanthanides fit with lanthanum between barium and hafnium. ${ }^{17}$ 


\section{KOCHEN, J, LANSING: MAPS FOR DISCOVERY}

Here again, we see how the map was changed by new evidence. With this alteration to the table came a surge in discovery. No less than nine transuranium elements were synthesized in the next 15 years. Furthermore, the periodic table of 1945 has helped to guide the search for new elements which is going on right now. Whether the future will someday bring about further changes in the table is uncertain, but if such a change becomes necessary it will certainly be the result of a radical shift in the way that we understand the structure of the atom.

\section{Conclusion}

The periodic table has indeed served as a general guide for the discovery of new elements. Discoverers have used it to detect gaps or anomalies in the patterns of atomic weights and valencies and to predict new elements to fit into those gaps or niches. It has also misguided discoverers when superficial similarities or patterns were attended to. It provided no clues to its users to distinguish between similarities and patterns that were profound and predictive and those that were not. Accompanying models of atomic structure, which can be viewed as a complementary map at another level, were needed for that. And the periodic table was revised in accordance with both the new evidence and the deeper models.

Thus the analogy to a topographic map must not be taken too seriously. Or, perhaps the notion of a topographic map should be revised to stress the regularities and patterns in what it maps, together with some indication and justification for which of these regularities represents an important law, rather than preservation of angles and distances. The periodic table guided discovery well when the laws it embodied-e.g. The Periodic Law, the Law of Triads-were used. Its anomalies helped in the search for new laws-e.g. the Pauli exclusion principle-which in turn helped to revise the table. It seems then that several kinds of concept-maps interact dynamically to represent with an increasing degree of approximation a picture of reality.

\section{References}

1. D. J.DE SOLLA PRICE, Some Aspects of 'World Brain' Notions, in: Information for Action M. KOCHEN, (Ed.), Academic Press, New York, 1975, pp. 189-190.

2. M. KOCHEN, Adaptive Mechanisms in Digital 'Concept' Processing, Proc. Joint Autom. Control Conf., AIEE 1962 pp. 49 -59.

3. M. E. STEVENS, A Machine Model of Recall, Proc. Int. Conf. on Information Processing, UNESCO Paris, 1959 pp. 309-315.

4. D. J. DE SOLLA PRICE, Little Science, Big Science. New York: Columbia University Press, 1963 , p. 29. 
5. M. KOCHEN, R. CRICKMAN, A. BLAIVAS, Distribution of Scientific Expertise as Recognized by Peer Consensus, Scientometrics 4 (1982) No. 2.

6. G. Evelyn HUTCHINSON, An Introduction to Population Ecology, Yale University Press, New Haven, 1978.

7. See especially Henry M. LEICESTER, The Historical Background of Chemistry, A.J. HOPKINS, Alchemy, Child of Greek Philosophy and Robert BOYLE, The Sceptical Chymist.

8. J. W. DOBEREINER, Darstellung der Verhältnisszahlen der iridischen Elemente zu Chemischen Verbindungen, Jena, 1816.

9. A. E. Beguyer DE CHANCOURTOIS, Compte Rendus, 54 (1862),

10. A. E. Beguyer DE CHANCOURTOIS, Compte Rendus, 55 (1862).

11. J. A. R. NEWLANDS, Chem. News, 7 (1865) 70.

12. L. MEYER, Die Modernen Theorien der Chemie und ihre Bedeuting fur die Chemische Statistik, Breslau (Wroclaw), 1864.

13. O. N. PISARZHEVSKY, Dimitri Ivanovich Mendeleev: His Life and Work, Moscow, 1954.

14. BOISBAUDRAN, Chemical and Spectroscopic Character of a New Metal, Gallium, discovered in the Blade of the Mine of Pierrefitte, in the Valley of Argeles, Pyrenees, Am. Chemist, 6, 146 [October 1875].

15. G. J. STONEY, Chem. News, 71 (1895) 67.

16. SEABORG, Glenn T., The Periodic Table-Tortuous Path to Man-made Elements, C\&E News, April 16 (1979) p. 46.

17. SEABORG, Ibid, p. 47. 